\section{A STUDY OF MINERS' NYSTAGMUS}

BY

\section{RAYMOND S. BROCK, M.D.}

This paper is based upon a study of nystagmus in fifteen pits of North Wales over a period of ten years. The nature of the eye movements is examined and the various theories as to their cause are discussed. The importance af psychological factors is considered and suggestions are offered, first, as to the prevention of disability, and, seçondly, regarding a more secure basis upon which disability may be assessed.

or

\section{The Eye Movements}

These are strikingly different from other forms of nystagmus. The "nystagmic" eye movements of colliers are more persistent in duration, are severer in degree, and more varied in type. They may be vertical, horizontal, oblique, or circumductory, but typically are more truly rotatory in direction. They may be of different magnitude in each eye, and the severity may vary in either eye. They are increased by darkness, by elevation of visual regard, and by sudden movements. They may be set up by emotional shock, such as sudden noise. They are lessened by lowered visual regard, by convergence, and by alcohol taken by mouth. They may be recorded on a moving sensitive plate by the " photonystagmagraph," which has been widely used on the Continent, or may be conveniently cinematographed by means of a simple apparatus such as one that I have constructed. By the latter means it is possible to study "stills" of the movements at intervals of one-sixteenth of a second, and these show that the actual excursion is not nearly so great as it appears to be when observed in the ordinary way.

Many theories have been put forward to account for the movements, but one point would appear to receive general acceptance-namely, the chronicity of the condition. An apparently abrupt onset is occasionally met with, but in eighty-three of my cases the average time of onset was 23.3 months, and some men noticed the condition coming on gradually over many years. This accords with the findings of other observers. Contrasted with the frequency of disability from accident at different ages, I have found that whereas this disability reaches its maximum among the younger and less experienced men, and tails off as the age groups rise, nystagmus, on the other hand, shows a relatively high incidence among the older workmen.

\section{Theories of Causation}

These may be classified as: (a) those suggesting some toxic agency; and $(b)$ those which postulate some form of fatigue. An "unknown hydrocarbon" suggested by Pechdo (1893) still remains undemonstrated as a cause. Robson (1923) has suggested carbon monoxide as responsible, but the disorder is sometimes rife in pits where that gas is absent. More recently German observers (Zeiss, 1932 ; Wiedersheim, 1934) have postulated two cerebral centres-one "position-keeping" and upset by dim light, etc., and the other "co-ordinating" and upset by chronic gas poisoning. The late Professor Haldane (1922a) spent several hours in an atmosphere of 80 per cent. $\mathrm{CH}_{4}$ and experienced no inconvenience whatsoever. On the other hand, it may be that in certain cases $\mathrm{CO}$ plays some part in promoting fatigue. Haldane (1931) demonstrated that this gas was formed in small quantities by the action of air on freshly cut coal, and Graham's analyses (1934) of mine air indicate in some pits enough $\mathrm{CO}$ to produce maximal blood concentrations of from 9.7 to 20 per cent. In America it has been reported that prolonged blood concentrations considerably lower than this (5 to 10 per cent.) may give rise to headache, dyspnoea, easy fatigue, tremor of the hands, etc. All these are characteristic in miners' nystagmus. Tachycardia is also common, and the question arises whether nystagmic miners may display any toxic myocardial changes. I have found on electrocardiography that in a series of twenty-four nystagmus cases showing tachycardia there was no indication of a relation between the pulse frequencies and any myocardial toxaemia. On the other hand, the cases all gave typical clinical indications of function disturbance consistent with the tachycardia noted. This may be of importance in assessing disability relative to this physical sign, since the general consensus of opinion appears to be that the myocardium is not in any way affected by tachycardia of a functional character.

A bacterial origin, though suggested, has never been demonstrated (Robson and Freeland Fergus). It has also been thought that infection might be sucked up the Eustachian tubes as a result of varying atmospheric pressure in journeying up and down in the cage, and giving rise to labyrinthine upset (Alabaster, 1933), but this brings us to the various "fatigue" theories, for one of the earliest suggestions was that of labyrinthine upset, arising from the maintenance of difficult working postures, and cases were described in six compositors, a paperhanger, and some other occupations involving a strained upward regard (Snell, 1907). The objections are that the disorder is only characteristic among colliers, and that the movements are entirely different in type, magnitude, and degree from those associated with labyrinthine upset. Moreover, the introduction of "machine mining," which has largely eliminated the old difficult posture, has not allowed any great reduction in the incidence of the disorder.

Ohm (1916) produced nystagmus resembling that of miners in puppies and kittens by keeping them in the dark, and the darkness of the mine is now generally regarded as the most important factor concerned. The condition is commoner in the poorer-lit pits, and is practically unknown in "open-light" pits. The incidence has been reduced in certain observed pits by improvement of lighting, and the late Professor Haldane's words remain true, that "it is only when coal is mined under conditions of excessive darkness that nystagmus results" (Haldane, 1922b).

As to why this should cause the characteristic movements no final answer has yet been found. Some think there may be an acquired pigmentary defect, but others may prefer the suggestion of Dr. T. Gwynne Maitland (1936) of Liverpool, that in conditions of low illumination two ocular reflexes normally occur: one which fixes the visual regard on an object appearing within the visual field, and the other by which the visual regard pursues the object if moving-a primitive protective mechanism. Gwynne Maitland has demonstrated experimental nystagmus set up by prolonged activation of these reflexes, and has pointed out how closely linked is the response with the subject's emotional state. At all events the condition of the mine, with the impending falls of coal which account for approximately half the total accidents, must certainly awaken the workers' emotional state, and it might be expected that the low illumination and the constant sense of danger should bring about cases of physiological and psychological breakdown after operating for any number of years. This is - my view of the disorder known as miners' nystagmus: that it is a breakdown of the man's ability to withstand the stresses of the mine. 
The condition is typically associated with psychoneurosis, and many of the symptoms are characteristic. For example, diarrhoea and precipitate micturition occasioned by excitement ; insomnia ; bad dreams ; nausea and even vomiting-usually noticed first thing in the morning, just like the nausea of pregnancy. Phobias of various kinds are often described. Of my cases, a consecutive series of 118 showed the following analysis:

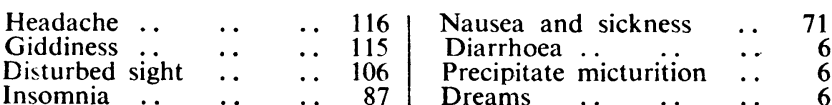

The physical signs are also characteristic-the tachycardia, sweating, marked tremor, twitching of facial muscles, and the general mental state. Men often show an appearance of "crystallized panic."

\section{Functional and Economic Factors}

Numerous references to the functional element in the disorder have been made from 1887 to the present time (Dickson, 1933), and it has become recognized that "the state known as miners' nystagmus may be a psychoneurosis arising independently of any disorder of the eye movements or of vision, while in other cases psychoneurotic symptoms arise from the disturbance of vision connected with nystagmus itself, just as in the psychoneuroses of warfare some old injury or organic affection often determines the locality of a hysterical paralysis or anaesthesia ... psychical conflicts of various kinds, sexual disturbances, or domestic worries all (may) contribute to the final breakdown" (Nystagmus Committee Report).

My experience in North Wales endorses this view. It has been found extremely rare for a man to give up work on account of eye movements alone. A close scrutiny of the case almost invariably discloses some other aetiological factor, which has finally determined cessation of work. The condition appears to depend upon the equation of two factors: the degree of strain, and the man's ability to withstand such strain ; and McCoull (1932) also has shown that the condition is much more likely to arise in men of impoverished mental equipment.

Strain of an economic nature frequently decides the balance of the equation. North Wales is a striking example of this. During the last decade the highest annual incidence in the whole coalfield was nearly four times more than the corresponding figures for the whole of Great Britain during the past twenty-six years. This high incidence in North Wales corresponded with a marked fall in the number of men employed, for trade was bad and many pits had to close.

While investigating the fifteen pits of North Wales I found that whenever large numbers of men were discharged there was at once a rush to be certified. In one case the average annual incidence for eight years was 0.37 per cent. of the men employed below ground, and never above 0.86 per cent., but during the year the pit closed the incidence jumped up to 2.59 per cent. In another pit the average rate for six years was 1.09 and never above 1.61 per cent., but during the last two years that the pit remained open, and while large numbers of men were being discharged, the rate jumped up to 6.72 per cent. Many of these men declared quite frankly that they could work if only they had the chance to do so, but, as they often added, " a man must live." Yet, having once been certified-the die having been castmany of them proceeded to develop chronic neuroses with tremor, tachycardia, sweating, etc., and a depressed and melancholy state of mind.
Here, then, we see how an additional economic factor may operate and may create the appearance of an epidemic. The claiming of compensation became widely known and customary. It became " the thing to do." It was this which I believe accounted for that large prevalence in North Wales mentioned earlier.

\section{Suggested Lines of Attack}

With all these facts in mind I see the following lines of attack in the prevention of disability from the malady: jii

1. Concerning the Panel Doctor.-Treatment of concurrent ill-health, such as anaemia, cardiac disease, focal infection, etcit

2. Concerning the Workman.-Avoidance of alcoholism apd excesses of all kinds.

3. Concerning the "Compensation" Doctor-Discovery of any particular stress, such as distance from pit bottom, defective light, sense of danger, prevalence of noise, etc., any one of which may predominate in taxing the man's tolerance. An appropriate change of job, if recommended to and accepted by the employer, may prevent a man's failure.

4. Concerning the Colliery Companies.-Diminution of stress by improvement of illumination and ventilation; whitewashing and stone-dusting. Setting up of experimental zones in which speed of work is slowed down. Provision of light work for affected men. Re-employment of men suitably recovered. Recognition of the nature of the condition and sympathetic co-operation in re-educating men to tolerate the full stresses once more. Possibly some form of pension scheme devised to remove the incentive to retire "on compensation."

5. Concerning the Medical Officers who have to Examine Applicants for Work at the Mines.-Namely, refusal of those showing impoverished mentality, deafness, or any defect calculated to render the stresses of the mine more acutely felt.

6. Concerning the Medical Referee.-Stricter assessment of disability on the basis that the disorder is not of an organic character, that eye movement is not proof of disablement, and that tachycardia is not a bar to employment. The writer suggests that an attempt should be made to decide whether the determining stress arises from the mine work itself or from independent sources.

\section{Summary}

1. Prolonged work below ground may bring about oscillation of the eyes which does not necessarily cause disablement.

2. When disability does arise it is usually due to an associated psychoneurosis.

3. The prevention of this depends upon: (a) recognition of the foregoing facts; $(b)$ the treatment of contributory disorders; (c) diminished stress in the mine; $(d)$ the barring of unsuitable applicants; $(e)$ improved economic conditions ; $(f)$ stricter assessment of disablement.

BibliograpHY

Alabaster, E. B. (1933). Trans. ophthal. Soc. U.K., 53, 571

Dickson, R. M. (1933). J. Army med. Corps, 60, 454.

Graham (1934). Trans. Inst. min. Engrs., 60, 222

Haldane, J. S. (1922a). Med. Res. Council Rep. No. 65 (First Rep. Miners' Nystagmus Cmtee.), p. 48.

(1922b). Ibid., p. 62

(1931). Trans. med.-leg. Soc., 24, 170.

McCoull, G. (1932). Newcastle med. J., 12, 208

Maitland, T. G. (1936). Paper to British Association, Blackpool

Ohm, J. (1922). Med. Res. Council Rep. No. 65 (First Rep. Miners' Nystagmus Cmtee.), p. 47.

Pechdo (1893). Bull. Mém. Soc. franç. Ophtal., 11, 394.

Robson, F. (1923). Proc. S. Wales Inst. Engrs., 39, Nos. 2 and 4. and Fergus, Freeland. Various writings.

Snell, S. (1907). Departmental Enquiry into Industrial Diseases.

Wiedersheim, O. (1934). Klin. Wschr., 13, 1335.

Zeiss, E. (1932). Ber. Versamml. dtsch. ophthal. Ges., 49, 389.

Calif. West. Med., 40, 19.

J. industr. Engng. Chem., 1922, 14, 229.

Med. Res. Council Rep. No. 65 (First Rep. Miners' Nystagmus Cmtee.), p. 11 